\title{
Investigation of the Lucas Loss Functioning during the Period 2000-2012 in Albania
}

\author{
Llambrini Sota \\ University "Pavaresia" Vlora, Albania, \\ email: llambrini.sota@unipavaresia.edu.al \\ Fejzi Kolaneci \\ University of New York in Tirana \\ email: fkolaneci@unyt.edu.al
}

\section{Doi:10.5901/ajis.2014.v3n4p127}

\begin{abstract}
The main objective of the study is to investigate the Lucas loss function as well as the Okun misery index over the period January 2000-June 2012 in Albania. Some results of the study include:The Central Limit Theorem is not valid for the quarterly economic loss in the sense of R. E. Lucas, Jr. during the specified period in Albania, at a confidence level $90.5 \%$. The quarterly economic loss caused by inflation and unemployment during the specified period in Albania is an unfair game, at the confidence level $99.9 \%$. The quarterly Okun misery index during the specified period in Albania is an unfair game, at the confidence level $94.2 \%$.In average, the Albanian people would trade off a 1 percent increase in the unemployment rate for a 2.35 percent increase in the inflation rate. The famous "Okun misery index" under-weights the economic loss of the Albanian people caused by joblessness.
\end{abstract}

Keywords: Lucas loss function, Okun misery index, Central Limit Theorem, fair game, unemployment rate, inflation rate, benevolent government.

\section{Introduction}

Well-known authors of modern Macroeconomics textbooks, like Blanchard (2011), Hall and Taylor (1997), Mankiw (2007) have assumed that the economic loss function (or welfare function) $\mathrm{W}$ depends on inflation rate $\mathrm{i}=\mathrm{i}(\mathrm{t})$ and unemployment rate $u=u(t): W=W(i, u)$. The citizens care about these two variables, which are random processes in the sense of Probability Theory. A large literature in economic sciences has tried to measure the losses from the inflation process. Milton Friedman (2008) and Robert Emerson Lucas, Jr. (2000) find the cost of inflation to be low: about 0.5 percent of the U.S. national income corresponds to the loss caused by 8-10 percent inflation rate. But Mankiw (2007) describes the question: "How costly is the inflation?" as one of the four major unsolved problems in Macroeconomics. Different results (mixed results) related to the economic losses caused by inflation or unemployment are reported by Clark and Oswald (1994), Dotsey and Ireland (1996), Di Tella, Mac Colluh, and Oswald (2001), etc. An optimal inflation path in Sidrauskitype model is developed by Den Haan (1990). Sargent, William, and Zha (2006) as well as Stock and Watson (2007) have analyzed in depth the inflation process in USA. Albanian economist and mathematicians have reported some estimation about the cost of inflation and unemployment. Survey evidence shows that when asked how they feel about feel about inflation and unemployment, Albanian individuals report different costs. In a panel that control the effect of inflation and unemployment, the Albanian citizens would trade off a 1 percent increase in the quarterly unemployment rate for a 2.35 percent increase in quarterly inflation rate. It is estimated that, in average, the gain from reducing the quarterly inflation rate from 4 percent to 3 percent is approximately equivalent to a reduction 0.43 percent in quarterly unemployment rate, see Shalari, Stringa, and Kolaneci (2012). In present study we use the Lucas loss function:

1) $W=W(i, u)=a i(t)+b u(t)+\varepsilon(t)$,

where $t$ denotes the time, positive constants $a$ and $b$ satisfy the condition $a+b=2$, and the error term (or disturbance term) $\varepsilon(t)$ follows a normal distribution with expectation $\mu=0$ and variance $\sigma^{2}(t)$, see Lucas $(2000),(2003)$. We consider two special cases: evidence).

$a=b=1$ (which corresponds to famous Okun's misery index), and $a=0.6, b=1.4$ (which corresponds to our survey

According to the opinions of Albanian citizens, the Okun's misery index under-weights the economic loss caused 
by unemployment (joblessness) process. It may be better for Albanian Government to adopt unemployment targeting objectives rather than inflation targeting objectives. This study aims to measure the Lucas loss function for Albania's economy during the period 2000 - 2012. The obtained mathematical results will motivate Albanian policy - makers to adopt effective defense strategies against unemployment and inflation. This topic is very important during recent economic crisis. The data set consists of the quarterly inflation rate and quarterly unemployment rate, associated with their successive differences, see Table 1. The sources of the data are INSTAT ( http://www.instat.gov.al) and Bank of Albania (http://www.bankofalbania.org). The Central Limit Theorem (CLT) explains why many probability distributions tend to be very close to the normal distribution. The amazing and counterintuitive thing about CLT is that no matter what the probability distribution of the population $\mathrm{X}$, the probability distribution of the sample mean approaches a normal curve. A contemporary version of the CLT is given by Kolmogorov (2002).

\section{The Central Limit Theorem}

If all random samples $\left(x_{1}, x_{2} \ldots \ldots x_{n}\right)$ of a reasonably large size $\mathrm{n}>30$ are selected from any random variable $\mathrm{X}$ with finite expectation $\mu$ and variance $\sigma^{2}$, then the probability distribution of the sample mean $\bar{x}$ is approximately normal with expectation $\mu$ and variance $\frac{\sigma^{2}}{n}$. This approximation improves with larger samples, as $n \rightarrow \infty$, see Kolmogorov (2002). The Kolmogorov-Smirnov-Lilliefors test is a supreme distance statistical test designed only for normal distribution; see Field (2009), Hogg (2009). The Shapiro-Wilk test for normality (W test) compares a set of sample data $\left(x_{1}, x_{2}, \ldots, x_{n}\right)$ against the normal distribution. The $\mathrm{W}$ test is of regression type and assesses how well the observed cumulative frequency distribution curve fits the expected normal cumulative curve. The $\mathrm{W}$ test for normality is sensitive to both skewness and kurtosis. In general, W test is more accurate that Kolmogorov-Smirnov-Lilliefors test, Cramer-Von Mises test, Durbin test, Chisquared test, and $b_{1}$ test. The remainder of this paper is organized as follows: Section 2 presents a statistical analysis of the quarterly inflation rate; Section 3 reports a statistical analysis of the quarterly unemployment rate; Section 4 provides the evolutionary dynamics of Okun misery index; Section 5 provides the dynamics of Lucas loss function; while Section 6 offers the conclusions.

\section{Statistical Analysis of the Quarterly Inflation Rate}

The term "inflation" refers to a rise in the consumer price index (CPI), which measures prices of a representative fixed basket of goods and services purchased by a typical consumer, see Mankiw (2007).

The formula for calculating the quarterly inflation rate is: Inflation rate $=\frac{P_{0}-P_{-1}}{P_{-1}} 100 \%$

where $\mathrm{P}_{0}$ denotes the current average price level, and $\mathrm{P}_{-1}$ denotes the average price level a quarter ago.

Today most well - known economists (Taylor, Mankiw, Sargent, Blanchard, etc)favor a low and stable inflation rate. The data set is quarterly inflation rate over the period January 2000- June 2012 in Albania, see Table. We compute the statistical parameters for the data:

\begin{tabular}{|l|c|}
\hline Sample size & 50 \\
\hline Sample mean & 1.6850 \\
\hline 95\% confidence interval for mean & $(1.1267,2.2433)$ \\
\hline Median & 2.0000 \\
\hline Sample variance & 3.860 \\
\hline Standard deviation & 1.965 \\
\hline Coefficient of variation & 1.166 \\
\hline Maximum & 7.80 \\
\hline Minimum & -1.80 \\
\hline Range & 9.60 \\
\hline Interquartile range & 2.57 \\
\hline Skewness & 0.455 \\
\hline Kurtosis & 0.711 \\
\hline
\end{tabular}

Using Kolmogorov - Smirnov- Lilliefors test as well as Shapiro - Wilk test for normality, we test the hypothesis:

$\mathrm{H}_{0}$ : The quarterly inflation rates over the period January 2000 - June 2012 for Albania follow a normal distribution. 
$\mathrm{H}_{1}$ : The quarterly inflation rates over the period January 2000 - June 2012 for Albania follow a non- normal distribution .Using SSPS (2009) we find the observed value of Kolmogorov - Smirnof - Lilliefors test 0.143 and the corresponding significance level 0.012 . Now, we apply Shapiro - Willk test is 0.949 and the corresponding significance level 0.03 .

Decision Rule: Reject the null hypothesis $\mathrm{H}_{0}$ at the confidence level $0.987=98.7 \%$. In other words, Kolmogorov's Central Limit Theorem is not valid for quarterly inflation rates during the period January 2000 - June 2012 in Albania, at the confidence 98.7\%'

Remark: To merit statistical analysis, the data set must measure variables of interest with sufficiently reasonable accuracy. We suggest that there is a substantial error or manipulation of the quarterly inflation rates in Albania over the specified period, which induce the inconsistency with Central Limit Theorem.

Definition (according to J.L. Stein, 1974). The inflation process $i(t)$ is said to be a fair game if the successive differences of inflation rates $i(t+1)-i(t)$ follow a normal distribution with mean equals zero. This important definition has found a variety of applications in business, finance, accounting, and economics, see Stein (1974), Lucas (2000), Sargent, Williams and Zha (2006), Stock and Watson(2007), etc. The successive differences of quarterly inflation rates in Albania over the specified period are given in Table 1. We present the statistical parameters related to these data set.

\begin{tabular}{|l|c|}
\hline Sample size & 49 \\
\hline Sample mean & 0.0786 \\
\hline $95 \%$ confidence interval for mean & $-0.4833,0.6404$ \\
\hline Median & 0.2000 \\
\hline Sample variance & 3.826 \\
\hline Standard deviation & 1.95603 \\
\hline Coefficient of variation & 24.89 \\
\hline Maximum & 5.70 \\
\hline Minimum & -4.30 \\
\hline Range & 10.00 \\
\hline Interquartile range & 1.90 \\
\hline Skewness & -0.001 \\
\hline Kurtosis & 0.890 \\
\hline
\end{tabular}

Test the hypothesis: $\mathrm{H}_{0}$ : The successive differences of the quarterly inflation rates during the period January 2000 June 2012 in Albania follow a normal distribution. $\mathrm{H}_{1}$ : The successive differences of the quarterly inflation rates during the period January 2000 - June 2012 in Albania follow a non - normal distribution. We apply the KSL test as well as SW test for normality. The observed value of KSL test is 0.137 and the corresponding level of significance 0.022 . The observed value of SW test is 0.966 and the associated significance 0.167 . Decision Rule: Reject the null hypothesis $\mathrm{H}_{0}$ at the confidence level $0.977=97.7 \%$. That is, at the confidence $97.7 \%$, the inflation process during the specified period in Albania, related to the quarterly inflation rates, is an unfair game in the sense of Stein.

\section{Statistical Analysis of the Quarterly Unemployment Rate}

Unemployment, as defined by the International Labor Organization (November 26, 2007), is the state in which the people are without jobs, they have actively looked for work within the past four weeks, and ready to start work within two weeks. The unemployment rate is the percentage of total labor force unemployed:

$$
\text { anemployment rate }=\frac{\text { anemployed workers }}{\text { total labor force }}
$$

The data set consists of quarterly unemployment rate during the period January 2000 - June 2012 in Albania, see Table 1. We compute the statistical parameters for the data set.

\begin{tabular}{|l|c|}
\hline Sample size & 50 \\
\hline Sample mean & 14.3388 \\
\hline $95 \%$ confidence interval for mean & $13.9421,14.7355$ \\
\hline Median & 13.8950 \\
\hline Sample variance & 1.949 \\
\hline Standard deviation & 1.39589 \\
\hline Coefficient of variation & 0.097 \\
\hline
\end{tabular}




\begin{tabular}{|l|c|}
\hline Maximum & 18.45 \\
\hline Minimum & 12.54 \\
\hline Range & 5.91 \\
\hline Interquartile range & 1.63 \\
\hline Skewness & 0.953 \\
\hline Kurtosis & 0.607 \\
\hline
\end{tabular}

Test the hypothesis:

$\mathrm{H}_{0}$ : The quarterly unemployment rates during the period January 2000 - June 2012 for Albania follow a normal distribution.

$\mathrm{H}_{1}$ : The quarterly unemployment rates during the period January 2000 - June 2012 for Albania follow a non normal distribution.

Using SPSS (2009) we calculate the observed value of KSL test 0.168 and the corresponding significance level 0.001 . Now, we apply SW test for normality. The observed value of SW test is 0.921 and the corresponding significance level 0.03 .

Decision rule: Reject the null hypothesis $\mathrm{H}_{0}$ at the confidence level $0.998=99.8 \%$. That is, Kolmogorov's CLT is not valid for quarterly unemployment rates during the specified period for Albania, at the confidence level $99.8 \%$. The successive differences of quarterly unemployment rates during the period January 2000-June 2012 are given in Table 1. Using SPSS (2009), we compute the statistical parameters for this data set.

\begin{tabular}{|l|c|}
\hline Sample size & 49 \\
\hline Sample mean & -0.0949 \\
\hline 95\% confidence interval for mean & $-0.2405,0.0507$ \\
\hline Median & -0.1100 \\
\hline Sample variance & 0.257 \\
\hline Standard deviation & 0.50702 \\
\hline Coefficient of variation & -5.343 \\
\hline Maximum & 1.64 \\
\hline Minimum & -1.56 \\
\hline Range & 3.20 \\
\hline Interquartile range & 0.30 \\
\hline Skewness & 1.089 \\
\hline Kurtosis & 5.337 \\
\hline
\end{tabular}

Test the hypothesis:

$\mathrm{H}_{0}$ : The successive differences of the quarterly unemployment rates during the period January 2000-June 2012 in Albania follow a normal distribution.

$\mathrm{H}_{1}$ : The successive differences of the quarterly unemployment rates during the period January 2000-June 2012 in Albania follow a non-normal distribution.

The observed value of KSL test is 0.224 and the corresponding significance level 0.000 . The observed value of SW test is 0.808 and the corresponding significance level 0.000 .

Decision Rule: Reject the null hypothesis $\mathrm{H}_{0}$ at the $0.999=99.9 \%$ confidence level. In other words, the unemployment process in Albania during the period January 2000-June 2012 is an unfair game, at the confidence 99.9\%. This is a sharp result.

\section{The Dynamics of Okun Misery Index}

The misery index is an economic indicator, initiated by well-known economist Arthur Melvin Okun, the Chairman of the Council of Economic Advisers under US President Lyndon B. Johnson in the 1960s. The Okun misery index denotes the sum of a country's inflation rate and unemployment rate. Hence, the Okun misery index is a special case of the Lucas loss function, corresponding to $a=b=1$ in formula (1). The Okun misery index captured the severity of two vexing issues of the time, inflation and unemployment. The Okun misery index is an important indicator of economic failure; the higher the total score, the worse the misery. There is no doubt that inflation and unemployment are two important criteria in judging the success or failure of the economic policy. However, a full evaluation of the economic performance must also include 
the measure of distributive justice: how equitably are overall gains distributed amongst all society's members? If a strong economy does not improve the economic conditions of most people or if economic conditions of most people or if economic gains are not fairly distributed, and then any claims of overall prosperity or of kinder society ring hollow. The Okun misery index is a measure of the miserably, see Hanke (2009). The data set is quarterly Okun misery index during the period January 2000-June 2012 in Albania, See Table 1. We compute the statistical parameters for the data set.

\begin{tabular}{|l|c|}
\hline Sample size & 50 \\
\hline Sample mean & 15.9508 \\
\hline 95\% confidence interval for mean & $15.1716,16.7300$ \\
\hline Median & 16.1250 \\
\hline Variance & 7.516 \\
\hline Standard deviation & 2.7415 .9 \\
\hline Coefficent of variation & 0.172 \\
\hline Maximum & 24.04 \\
\hline Minimum & 11.21 \\
\hline Range & 12.83 \\
\hline Interquartile range & 3.58 \\
\hline Skewness & 0.461 \\
\hline Kurtosis & 0.501 \\
\hline
\end{tabular}

Using SPSS (2009), we test the following hypothesis: distribution.

$\mathrm{H}_{0}$ : The quarterly Okun misery index during the period January 2000- June 2012 in Albania follows a normal

$\mathrm{H}_{1}$ : The quarterly Okum misery index during the period January 2000- June 2012 in Albania follows a non-normal distribution. The observed value of KSL test is 0.097 and the significance 0.200 . The observed value of SW test is 0.953 and the significance 0.084 .

Decision Rule: Reject the null hypothesis $\mathrm{H}_{0}$ at the $0.915=91.5 \%$ level of confidence. The successive differences of the quarterly misery index are given in Table 1 Please see below the statistical parameters related to this data set.

\begin{tabular}{|l|c|}
\hline Sample size & 49 \\
\hline Sample mean & -0.0308 \\
\hline 95\% confidence interval for mean & $-0.6543,0.5927$ \\
\hline Median & 0.0500 \\
\hline Variance & 4.712 \\
\hline Standard deviation & 2.17066 \\
\hline Coefficent of variation & -70.476 \\
\hline Maximum & 7.34 \\
\hline Minimum & -4.70 \\
\hline Range & 12.04 \\
\hline Interquartile range & 2.01 \\
\hline Skewness & 0.513 \\
\hline Kurtosis & 2.073 \\
\hline
\end{tabular}

Test the hypothesis:

$H_{0}$ : The successive differences of the quarterly Okun misery index during the period January 2000 - June 2012 in Albania follow a normal distribution.

$\mathrm{H}_{1}$ : The successive differences of the quarterly Okun misery index during the period January 2000 - June 2012 in Albania follow a non-normal distribution. We calculate the observed value of KSL test 0.120 and the significance 0.076 . The observed value of SW test is 0.955 and the corresponding significance 0.057 .

Decision Rule: Reject the null hypothesis at the confidence level $0.942=94.2 \%$. That is, at the confidence $94.2 \%$, the misery process during the period January 2000 - June 2012 is an unfair game. Money Week magazine (October 28, 2010) reported the Okun misery index across the world's leading nations. The countries with the lowest Okun misery index are: Switzerland 3.50, Japan 4.80, Norway 4.90, Mexico 8.37, and Australia 8.80. The countries with the highest Okun misery index are South Africa 28.90, Spain 24, Greece 19.23, India 18.40, and Argentina 17.20. The USA has a rating of 13.10 and the UK 13.30. Back in June 1980, during Jimmy Carter's Presidency, the USA reached an all time 
high Okun misery index 21.98.

\section{The Dynamics of Lucas Loss Function}

The contemporary scientific literature on Macroeconomic Policy has been using the concept of "social performance function over inflation and unemployment", especially in mathematical models of benevolent governments that want to minimize the social loss function, or equivalently, to maximize the welfare function of representative consumer. The Lucas loss function, defined by formula (1), has become an important tool in Macroeconomic thinking. The particular specifications for the Lucas loss function $\mathrm{W}(\mathrm{i}, \mathrm{u})=\mathrm{ai}+\mathrm{bu}+\varepsilon$ differs in terms of the relative weights attached to the two random processes $i=i(t)$ and $u=u(t)$, see Welsch (2007). The case of Albania corresponds to the relative weights $a=$ 0.6 and $b=1.4$. The observed values of quarterly Lucas loss function during period January $2000-$ June 2010 for Albania are given in Table 1.

We compute the statistical parameters for the data set.

\begin{tabular}{|l|c|}
\hline Sample size & 50 \\
\hline Sample mean & 21.2418 \\
\hline $95 \%$ confidence interval for mean & $20.3717,22.1119$ \\
\hline Median & 20.8100 \\
\hline Variance & 9.374 \\
\hline Standard deviation & 3.06179 \\
\hline Coefficient of variation & 0.144 \\
\hline Maximum & 31.57 \\
\hline Minimum & 15.86 \\
\hline Range & 15.71 \\
\hline Interquartile range & 4.32 \\
\hline Skewness & 0.803 \\
\hline Kurtosis & 1.314 \\
\hline
\end{tabular}

Test the hypothesis:

$\mathrm{H}_{0}$ : The quarterly loss during the period January 2000 - June 2012 for Albania follows a normal distribution. $\mathrm{H}_{1}$ : The quarterly loss during the period January 2000 - June 2012 for Albania follows a non - normal distribution.

Using KSL test as well as SW test for normality and SPSS (2009), we find the observed of KSL test 0.091, the corresponding significance 0.200 , the observed value of SW test 0.961 , and corresponding significance 0.094 .

Decision Rule: Reject the null hypothesis $\mathrm{H}_{0}$ at the confidence level $0.905=90.5 \%$. That is, the Lucas economic loss function during the period January 2000 - June 2012 for Albania is inconsistent with Central Limit Theorem, at the confidence $90.5 \%$. The successive differences of the quarterly Lucas loss function over the period January 2000 - June 2012 for Albania are given in Table 1. We calculate the statistical parameters for this data set.

\begin{tabular}{|l|c|}
\hline Sample size & 49 \\
\hline Sample mean & -0.0820 \\
\hline $95 \%$ confidence interval for mean & $-1.0537,0.8896$ \\
\hline Median & -0.2000 \\
\hline Variance & 11.443 \\
\hline Standard deviation & 3.38276 \\
\hline Coefficient of variation & -41.253 \\
\hline Maximum & 11.61 \\
\hline Minimum & -10.75 \\
\hline Range & 22.36 \\
\hline Interquartile range & 2.03 \\
\hline Skewness & 0.899 \\
\hline Kurtosis & 6.499 \\
\hline
\end{tabular}

Test the hypothesis:

$\mathrm{H}_{0}$ : The successive differences of the Lucas loss function during the period January 2000 - June 2012 for Albania follows a normal distribution. 
$H_{1}$ : The successive differences of the Lucas loss function during the period January 2000 - June 2012 for Albania follow a non-normal distribution. Using SPSS (2009) we find the observed value of KSL test 0.201, the significance 0.000 , the observed value of SW test 0.792 , and the significance 0.000 .

Decision Rule: Reject the null hypothesis $\mathrm{H}_{0}$ at the confidence level $0.999=99.9 \%$. In other words, the Lucas loss process during the period January 2000 - June 2012 for Albania is an unfair game at the confidence level $99.9 \%$. This is a sharp result.

\section{Conclusions}

This study investigates three types of Macroeconomics models during the period January 2000 - June 2012 in Albania:

(1) Monetary models focused on quarterly inflation rate dynamics.

(2) Labour models focused on quarterly unemployment rate dynamics.

(3) Welfare models focused on Okun misery index and Lucas loss function.

According to reported well-being data on a random and representative sample of 1800 people across Albania during the years 2011 - 2012 we find out that, in average, Albanian people would trade off a 1 percent increase in the unemployment rate for a 2.35 percent increase in the inflation rate during the period $2000-2012$. Therefore the famous "Okun misery index" $\mathrm{W}=\mathrm{i}+\mathrm{u}$ under weights the economic loss of the Albanian people caused by joblessness. The quarterly changes in the happiness are more strongly correlated with changes in quarterly unemployment rate than with changes in the quarterly inflation rate. An important question we have addressed in the study is whether inflation targeting and stabilization strategies alone developed by the Bank of Albania during these last six years promise important in welfare? The answer of this question is №. For the case of Albania over the period January 2000 - June 2012, the unemployment process depresses reported well - being more than inflation process does. The potential games from the improved inflation targeting and stabilizing policies are, in average, approximately 43 percent of the expected economic loss caused by the unemployment process. Some results of the study include :

The quarterly inflation rates during the period January 2000 - June 2012 in Albania contradict the Kolmogorov's Central Limit Theorem, at the confidence level $98.7 \%$.

The inflation process in Albania during the period January 2000 - June 2012, related to the quarterly inflation rate, is an unfair game, at the confidence level $97.7 \%$.

The Kolmogorov's Central Limit Theorem is not valid for quarterly unemployment rate during the period January 2000 - June 2012 in Albania, at the confidence level 99.8\%.

The unemployment process in Albania during the period January 2000 - June 2012, related to the quarterly unemployment rate, is an unfair game, at the confidence level $99.9 \%$.

The quarterly Okun misery index during the period January 2000 - June 2012 in Albania is inconsistent with the Central Limit Theorem, at the confidence level $91.5 \%$.

The quarterly Okun misery index during the period January 2000 - June 2012 in Albania is an unfair game, at the confidence level $94.2 \%$.

The observed data for the quarterly economic loss (in the sense of R. E. Lucas, Jr.) during the period January 2000 - June 2012 in Albania contradicts the Kolmogorov's Central Limit Theorem, at the confidence level 90.5\%.

The quarterly economic loss (in the sense of R. E. Lucas, Jr.) during the period January 2000 - June 2012 in Albania is an unfair game, at the confidence level $99.9 \%$.

The contradiction between the quarterly inflation rate (or quarterly unemployment rate, or quarterly misery index, or quarterly Lucas loss function) and Kolmogorov's Central Limit Theorem is serious, as this theorem represents a fundamental result of the Modern Probability Theory. An important question posed by our study is : How can the Albanian Government successfully fight the inflation process, unemployment process, as well as the economic loss process as an "unfair game" in the sense of J. L. Stein? The investigation of the Lucas loss function in Albanian economy during the period 2000 - 2012, using mathematical models and data set, is an effective Macroeconomics research. The Albanian Government must apply optimal economic and policy strategies, in order to reduce step - by - step the Lucas loss function using this approach. Today we are able to develop a much sharper quantitative estimation of the potential of changes in Government's policy to improve Albanian peoples' lives than was possible 12 years ago.

\section{References}

Blanchard, O. (2011). Macroeconomics, Pearson, USA.

Clark, A. And Oswald, A. J. (1994). Unhappiness and unemployment, Economic Journal, 104(5), pp 648 - 659. 
Den Haan, Wouter J. (1990). The optimal inflation path in a Sidrauski - Type model with uncertainty, Journal of Monetary Economics, 25 , pp $389-409$.

Di Tella, R., R. J. MacCalluh, and A. J. Oswald (2001). Preferences over inflation and unemployment : evidence from surveys of happiness, American Economic Review, 91(1), 335 - 341.

Dotsey, Michael and Peter Ireland (1996). The welfare cost of inflation in general equilibrium, Journal of Monetary Economics, $37, \mathrm{pp} 29$ $-47$.

Field, A. (2009). Discovering Statistics Using SPPS, 3 edition, London: Sage.

Friedman, M. (2008). The Optimum Quantity of Money, Aldine Transaction, USA.

Hall, R. E. And Taylor, J. (1997). Macroeconomics, $5^{\text {th }}$ edition, New York, Norton Press.

Hanke, S. H. (2009). The misery index: A reality check, Cato Institute, www.cato.org

Hogg, R. V. (2009). Probability and Statistical Inference, 8 edition, Prentice Hall.

International Labor organization (2007, 11.26). Resolution concerning statistics of the economically active population, employment, unemployment and underemployment. Retrieved from: http://www.ilo.org/public/english/bureau/stat.pdf

Kolmogorov, A. N. (2002). Probability Theory, Moscow: Nauka.

Lucas, R. E, Jr. (2000). Inflation and welfare, Econometrica, Vol.68, No.2, pp 247 - 274.

Lucas, R. E, Jr. (2003). Macroeconomic priorities, working paper, 32p.

Lucas, R. E, Jr. (2009). Ideas and growth, Economica, Vol.76, No.1, pp 1 - 19.

Mankiw, N. Gregory (2007). Macroeconomics, $7^{\text {th }}$ ed. New York: Worth Publishers.

Sargent, T., Williams, J., and Tao Zha (2006). Shocks and government beliefs: The rise and fall of American inflation, American Economic Review, 94(3), 1193 - 1224.

Shalari, O., Stringa, A., and Kolaneci, F. (2012). Statistical analysis of the relationship between inflation rate and unemployment rate in Albania, presented in International Conference developed by the University of Tirana, Faculty of Economics.

Stein, J. L. (1974). Unemployment, inflation, and monetarism, American Economic Review, 92(5), pp 721 - 756.

Stock, J. H. And Watson, M. W. (2007). Why has US inflation become harder to forecast? Journal of Money, Credit, and Banking, 39(1), pp $3-33$.

Taylor, T. (2008). Principles of Economics, USA, Freeload Press.

Welsch, H. (2007). Macroeconomics and life satisfaction. Revisiting the "misery index", Journal of Applied economics, Vol.8, No.2, pp $237-251$.

\section{Apendix}

Table 1. Quarterly inflation rates, unemployment rates, Okun misery index, Lucas loss function, and their successive differences

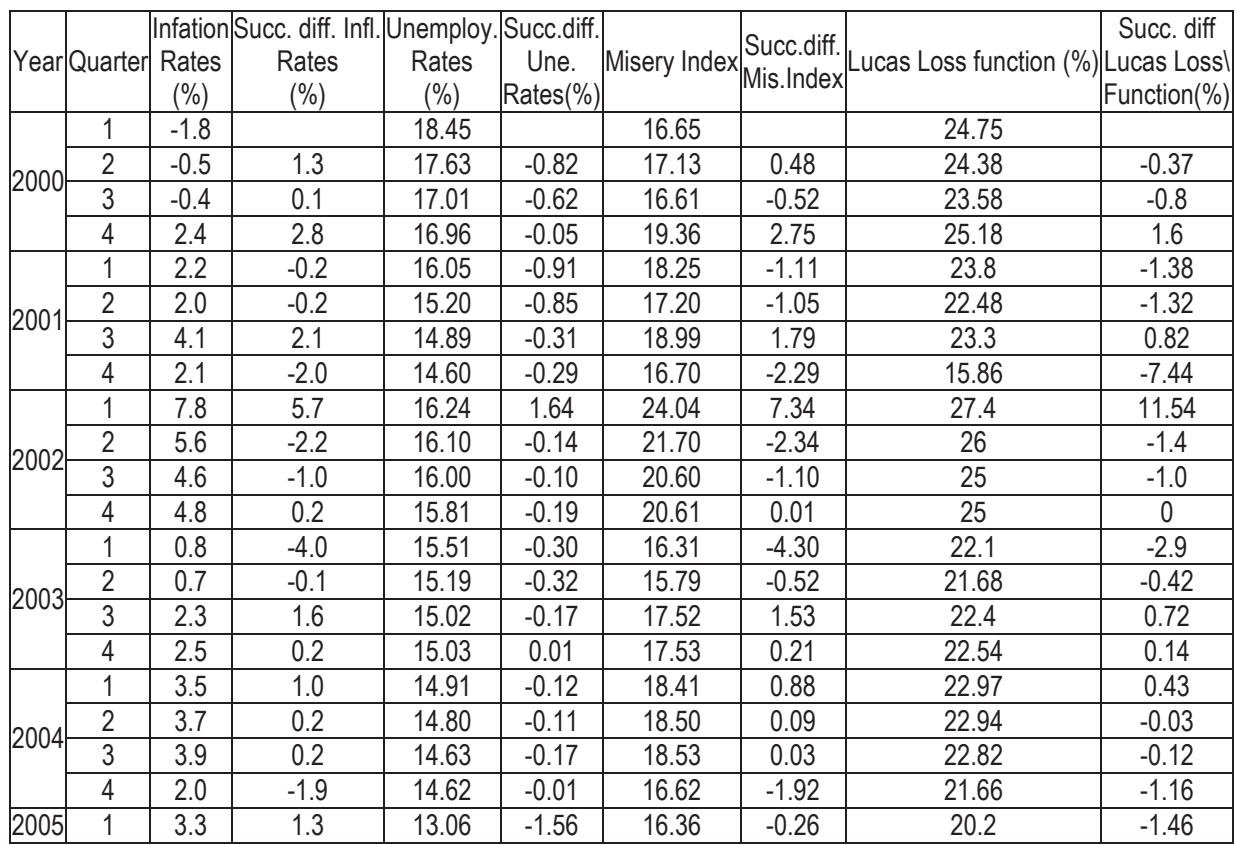




\begin{tabular}{|c|c|c|c|c|c|c|c|c|c|}
\hline & 2 & -1.0 & -4.3 & 12.66 & -0.40 & 11.66 & -4.70 & 17.12 & -3.08 \\
\hline & 3 & -1.4 & -0.4 & 12.61 & -0.05 & 11.21 & -0.45 & 16.8 & -0.32 \\
\hline & 4 & 1.9 & 3.3 & 14.18 & 1.57 & 12.28 & 0.07 & 21 & 4.2 \\
\hline & 1 & 2.0 & 0.1 & 14.03 & -0.15 & 16.03 & 3.75 & 20.8 & -0.2 \\
\hline 2006 & 2 & 0.2 & -1.8 & 13.89 & -0.14 & 14.19 & -1.84 & 19.5 & -1.3 \\
\hline$\angle 000$ & 3 & -1.2 & -1.3 & 13.81 & -0.08 & 12.61 & -1.58 & 18.6 & -0.9 \\
\hline & 4 & 1.8 & 3.0 & 13.70 & -0.11 & 15.50 & 2.89 & 20.26 & 1.66 \\
\hline & 1 & 2.2 & 0.4 & 13.68 & -0.02 & 15.88 & 0.38 & 20.47 & 0.21 \\
\hline 2007 & 2 & -0.8 & -3.0 & 13.46 & -0.22 & 12.66 & -3.22 & 18.36 & -2.11 \\
\hline 2001 & 3 & 0.4 & 1.2 & 13.19 & -0.27 & 13.59 & 0.93 & 18.7 & 0.34 \\
\hline & 4 & 1.7 & 0.9 & 13.38 & 0.19 & 15.08 & 1.49 & 19.75 & 1.05 \\
\hline & 1 & 2.4 & 0.7 & 13.06 & -0.32 & 15.46 & 0.38 & 19.72 & -0.03 \\
\hline 2008 & 2 & -0.3 & -2.7 & 12.66 & -0.40 & 12.36 & -3.10 & 17.54 & -2.18 \\
\hline & 3 & -0.8 & -0.5 & 12.61 & -0.05 & 11.81 & -0.55 & 17.17 & -0.37 \\
\hline & 4 & 1.2 & 2.0 & 12.54 & -0.07 & 13.74 & 1.93 & 18.27 & 1.1 \\
\hline & 1 & 1.8 & 0.6 & 12.66 & 0.12 & 14.46 & 0.72 & 18.80 & 0.53 \\
\hline 2000 & 2 & -0.1 & -1.9 & 12.66 & 0.00 & 12.56 & -1.90 & 17.66 & -1.14 \\
\hline 2009 & 3 & -0.7 & -0.6 & 12.75 & 0.09 & 12.05 & -0.51 & 17.43 & -0.23 \\
\hline & 4 & 2.2 & 2.9 & 13.71 & 0.96 & 15.91 & 3.86 & 20.51 & 3.08 \\
\hline & 1 & 3.0 & 0.8 & 13.88 & 0.17 & 16.88 & 0.97 & 21.23 & 0.72 \\
\hline 2010 & 2 & -1.0 & -4.0 & 13.82 & -0.06 & 12.82 & -4.06 & 18.74 & -2.49 \\
\hline 2010 & 3 & -0.6 & 0.4 & 13.50 & -0.32 & 12.90 & 0.08 & 18.54 & -0.2 \\
\hline & 4 & 1.8 & 2.4 & 13.49 & -0.01 & 15.29 & 2.39 & 19.96 & 1.42 \\
\hline & 1 & 2 & 0.2 & 14 & 0.51 & 16 & 0.71 & 31.57 & 11.61 \\
\hline 2 & 2 & 2.5 & 0.5 & 13.8 & -0.2 & 16.3 & 0.3 & 20.82 & -10.75 \\
\hline 2011 & 3 & 2.3 & -0.2 & 13.85 & 0.05 & 16.1 & -0.2 & 20.77 & -0.05 \\
\hline & 4 & 2.4 & 0.1 & 13.9 & 0.05 & 16.3 & 0.2 & 24.26 & 3.49 \\
\hline & 1 & 2.4 & 0 & 13.95 & 0.05 & 16.35 & 0.05 & 20.97 & -3.29 \\
\hline 20 & 2 & 2.35 & -0.05 & 13.8 & -0.15 & 16.15 & -0.2 & 20.73 & -0.24 \\
\hline
\end{tabular}


